\title{
Penggabungan Metode MEC dan AHP dalam Penentuan Bantuan Rumah Tidak Layak Huni
}

Combination of MEC and AHP Method to Determine Uninhabitable Home Assistance

\author{
Rakhmad Kuswandhie $^{* 1}$ Yogi Primadasa ${ }^{2}$ \\ ${ }^{1,2}$ Jl. Yos Sudarso, Lubuk Linggau Timur. II, Kota Lubuklinggau, Sumatera Selatan 31613 \\ ${ }^{1,2}$ Sistem Informasi STMIK Bina Nusantara Jaya Lubuklinggau \\ e-mail: ${ }^{* 1}$ ma2dxl@gmail.com, ${ }^{2}$ yogiak45@gmail.com
}

\begin{abstract}
Abstrak
Rumah tidak layak huni murapakan kondisi yang tidak ideal dimana bangunan tersebut tidak memenuhi persyaratan untuk dihuni. Kenyataannya rumah tidak layak huni sangat berhubungan dengan pemukiaman kumuh karena pada dasarnya didaerah permukiman kumuh tergambar kemiskinan masyarakat. Program Rehabilitasi atau bedah rumah tidak layak huni merupakan program yang diterapkan Pemerintah Kota Lubuklinggau untuk upaya meningkatkan rumah warga yang tidak layak huni yang ada di Kota Lubuklinggau menjadi layak huni. Permasalahan yang sering terjadi adalah proses penyeleksiaan masih bersifat subjektif, yang mana penyeleksian dilakukan dengan presepsi dari masing-masing anggota Dinas Sosial, belum juga mengingat banyaknya calon penerima yang akan menerima bantuan rehabilitasi rumah yang akan diseleksi dalam daerah tersebut, sehingga penyeleksi sangat merasa kesulitan dalam mengadakan penyeleksian bantuan ini. Dari permasalahan tersebut Sistem Pendukung Keputusan merupakan alternatif untuk membantu Pemerintah Kota dalam penyeleksian penerimaan bantuan bedah rumah tidak layak huni. Dari data kandidat penerima bantuan beda rumah tidak layak huni yang sudah di kumpulkan oleh Dinas Sosial ini akan di seleksi ulang di tambah kriteria-kriteria yang menjadi pendukung. Kriteria-kriteria seperti penghasilan, dinding rumah, lantai, jenis rumah, luas bangunan dan atap rumah ini digunakan untuk mendukung penelitian ini. Metode yang digunakan dalam penelitian ini dibantu dengan menggunakan penggabungan metode MEC dan AHP. Metode MEC digunakan untuk menentukan kriteria yang berpengaruh seperti penghasilan, dinding rumah, lantai, jenis rumah, luas bangunan dan atap rumah. Metode AHP digunakan untuk menentukan bobot masing-masing kriteria.
\end{abstract}

Kata Kunci-Sistem Pendukung Keputusan, Seleksi, MEC,AHP

\begin{abstract}
Uninhabitable homes are not ideal conditions where the building does not meet the requirements to be inhabited. The fact is that uninhabitable housing is very much related to slum settlement because basically in the slums area, poverty is reflected in the community. Rehabitation or surgery for uninhabitable houses is a program implemented by the Lubuklinggau City Government in an effort to improve non-habitable houses in Lubuklinggau City to become habitable. The problem that often occurs is that the selection process is still subjective, where selection is done by the perception of each member of the Social Service, not to mention the large number of prospective recipients who will receive housing rehabilitation assistance to be selected in the area, so that selectors feel very difficult conduct this selection of assistance. Of these problems the Decision Support System is an alternative to assisting the City Government in selecting receipts for uninhabitable home surgical assistance. From the data of the candidate recipients of different types of uninhabitable homes that have been collected by the Social Service, they will be re-selected plus the criteria that become supporters. Criteria such as income, house walls, floors, type of house, building area and roof of the house were used to support this research. The method used in this study was assisted by using a combination of the MEC and AHP methods. The MEC method is used to determine influential
\end{abstract}


criteria such as income, house walls, floors, type of house, building area and roof of a house. AHP method is used to determine the weight of each criterion.

Keyword - Decision support system, selection, MEC,AHP

\section{PENDAHULUAN}

Kebutuhan primer atau dasar yang dibutuhkan pemenuhan dan merupakan salah satu kebutuhan yang dibutuhkan jasmani dan bersifat material adalah rumah. Rumah juga menjadi salah satu aspek dari sebuah kesejahteraan sosial. Hal ini menandakan bahwa kebutuhan rumah akan mempengaruhi derajat kesejahteraan masyarakat dan harus mendapat pemenuhan. Pelaksanaan fungsi sosial masyarakat tersebut akan mengalami gangguan atau hambatan jika tidak terpenuhinya kebutuhan rumah. Banyak tempat tinggal warga yang dikategorikan Rumah Tidak Layak Huni (RTLH) yang disebabkan masih cukup besarnya jumlah masyarakat yang memiliki penghasilan rendah di Indonesia. Hal ini dijadikan sorotan pemerintah setempat terutama untuk Kota Lubuklinggau.

Program Rehabilitasi rumah tidak layak huni merupakan stimulan dalam bentuk bantuan supaya rumah layak huni dapat ditempati oleh rakyat miskin. Program rehabilitasi rumah tidak layak huni ini ditujukan agar rumah layak huni dapat dimiliki oleh masyarakat yang memiliki pendapatan yang masih rendah. Tujuan lainnya adalah agar taraf hidup masyarakat dapat ditingkatkan menjadi lebih baik dan berkehidupan yang layak, bersih serta sehat sehingga bantuan tersebut dapat bermanfaat dan dalam jangka yang panjang dapat dirasakan kemanfaatannya. Berdasarkan informasi dari perangkat daerah Kota Lubuklinggau khususnya Kelurahaan Dempo disampaikan bahwa yang sering terjadi adalah proses penyeleksiaan masih bersifat subjektif, yang mana penyeleksian dilakukan dengan presepsi dari masing-masing anggota Dinas Sosial, belum juga mengingat banyaknya calon penerima yang akan menerima bantuan rehabilitasi rumah yang akan diseleksi dalam daerah tersebut, sehingga penyeleksi sangat merasa kesulitan dalam mengadakan penyeleksian bantuan ini.

Dari permasalahan tersebut Sistem Pendukung Keputusan merupakan alternatif untuk membantu Pemerintah Kota dalam penyeleksian penerimaan bantuan bedah rumah tidak layak huni. Sistem pendukung keputusan ini dibantu dengan menggunakan penggabungan metode MEC dan AHP. Metode MEC digunakan untuk menentukan kriteria yang berpengaruh seperti penghasilan, dinding rumah, lantai, jenis rumah, luas bangunan dan atap rumah. Metode AHP digunakan untuk menentukan bobot masing-masing kriteria.

Dalam penelitian sebelumnya metode WP pada Sistem Pendukung Keputusan dapat digunakan dalam proses pemilihan/penentuan penerima bantuan perbaikan rumah. Sistem pendukung keputusan ini adalah salah satu cara agar diperoleh hasil yang lebih baik karena dapat melakukan penilaian lebih objektif dan dapat dipertanggung jawabkan, sebab sistem yang dihasilkan pada penelitian ini telah menerapkan metode metode WP yang dihitung dengan perhitugan empiris sehingga tingkat kebenarannya dapat dilakukan pengujian dan dapat dilakukan analisa apakah hasil pengambilan keputusannya benar atau salah[1]. Informasi alternatif keputusan yang dihasilkan dari Sistem pendukung keputusan ini untuk memilih secara cepat penerima bantuan rumah tidak layak huni. Tingkat kinerja instansi dapat direpresentasikan dengan sistem dalam bentuk grafik sehingga dengan adanya informasi ini, kebijakan yang dibuat pimpinan sesuai dan efektif[2]. Penggunaan indikator-indikator yang secara pasti dengan menilai pembobotan pada tiap indikator, menjadikan kelayakan penerima RUTILAHU dinilai dengan lebih obyektif. Penilaian berdasarkan indikator dengan pembobotan penilaian dengan memanfaatkan metode AHP menjadikan penilaian RUTILAHU lebih efektif. Program SPK ini memberikan keputusan yang tepat, cepat dan obyektif[3]. Pengambilan keputusan menggunakan metode Multi Factor Evaluation Process dilakukan secara subyektif dan intuitif dengan menimbang beberapa faktor yang berpengaruh terhadap alternatif[4]. Penelitian lain yang relevan adalah dengan digunakannya metode Multi Criteria Evaluation (MCE) untuk penentuan 
kesesuaian wisata bahari. Pengklasifikasian kelayakan tanah untuk ternak ikan nila di Bangladesh dengan pendekatan SIG menggunakan Metode MCE [5]. Penggunaan Metode Multi Criteria Evaluation (MCE) untuk analisis kesesuaian lahan dengan kriteria yang lebih dari satu, penentuan nilai bobot dari kriteria ditentukan secara bersama[6]. Dari referensi jurnal diatas diharapkan, sistem pendukung keputusan dengan menggabungkan metode MEC dan AHP ini bisa membantu pihak yang berkaitan dalam seleksi penerimaan bantuan rumah tidak layak huni.

\section{METODE PENELITIAN}

\subsection{Sistem Pendukung Keputusan}

Sistem Pendukung Keputusan merupakan sistem informasi yang interaktif untuk membantu pengambilan keputusan dalam situasi semitersktruktur dan situasi yang tidak terstruktur. Sistem Pendukung Keputusan merupakan penerapan suatu sistem informasi yang bertujuan untuk membantu pimpinan selaku pengambil keputusan[1][4][7][8].

\subsection{Tahapan AHP}

Tahapan pada AHP disusun sebagai berikut[9] :

a. Menyusun hirarki dari permasalahan yang dihadapi

Level 1

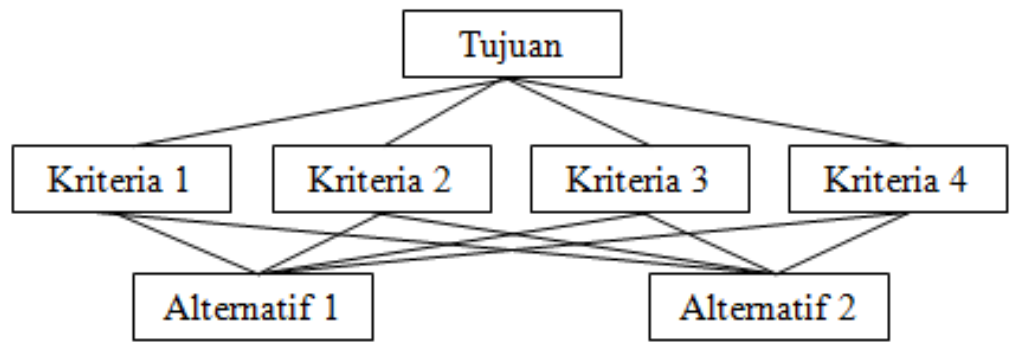

Gambar 1 Struktur Hierarki AHP

b. Penilaian kriteria dan alternatif

Pernilaian kriteria dan alternatif melalui perbandingan berpasangan. Tabel perbandingan dapat dilihat di bawah ini

Tabel 1 Skala Nilai Perbandingan Berpasangan

\begin{tabular}{|c|l|}
\hline $\begin{array}{c}\text { Intensitas } \\
\text { Kepentingan }\end{array}$ & \multicolumn{1}{|c|}{ Definisi } \\
\hline 1 & Tingkat kepentingan kedua elemen adalah sama \\
\hline 3 & $\begin{array}{l}\text { Satu elemen sedikit lebih penting dari pada } \\
\text { elemen yang lain. }\end{array}$ \\
\hline 5 & $\begin{array}{l}\text { Satu elemen lebih penting dari pada elemen yang } \\
\text { lain }\end{array}$ \\
\hline 7 & $\begin{array}{l}\text { Satu elemen jelas lebih mutlak penting daripada } \\
\text { elemen lainnya }\end{array}$ \\
\hline 9 & $\begin{array}{l}\text { Elemen yang satu adalah mutlak penting dari } \\
\text { pada elemen yang lain }\end{array}$ \\
\hline $2,4,6,8$ & $\begin{array}{l}\text { Nilai-nilai antara dua nilai pertimbangan yang } \\
\text { berdekatan }\end{array}$ \\
\hline Kebalikan & \\
\hline
\end{tabular}


Perbandingan dilakukan dengan memperitmbakan antara elemen, dimana penentuan elemen tersebut ditentukan kebijakan si pembuat keputusan. Proses ini dimulai dari level hirarki paling atas yang ditujukan untuk memilih kriteria, kemudian diambil elemen yang akan dibandingkan. Contoh proses matrik perbandingan ini bisa di lihat pada tabel 2 dibawah ini :

Tabel 2 Contoh Matriks Perbadingan berpasangan

\begin{tabular}{|c|c|c|c|}
\hline & A1 & A2 & A3 \\
\hline A1 & 1 & & \\
\hline A2 & & 1 & \\
\hline A3 & & & 1 \\
\hline
\end{tabular}

c. Menghitung prioritas dan konsistensi pembobotan.

Langkah berikutnya adalah melakukan penghitungan prioritas. Prioritas dari matrik diperoleh melalui proses berikut:

1) Nilai yang ada pada elemen tiap kolom dilakukan penjumlahan

2) Melakukan operasi pembagian pada tiap elemen pada kolom dibagi dengan jumlah kolom berkesesuaian.

3) Hitung prioritas untuk melakukan operasi penjumlahan tiap baris dan membaginya dengan jumlah elemen.

d. Menampilkan hasil penghitungan dari alternatif yang dipertimbangkan.

Setelah proses pembobotan untuk level kriteria dan alternatif dikerjakan, maka selanjutnya akan ditampilkan prioritas global yang merupakan hasil dari perkalian prioritas lokasi dengan prioritas kriteria yang bersangkutan, kemudian menjumlahkannya untuk tiap lokasi.

\subsection{Metode MEC}

Metode MEC menggunakan perhitungan sejumlah kriteria, memproses pembobotan dan memberi penilaian pada setiap kriteria dengan kemungkinan hasil untuk perangkingan. Metode multicriteria dibagi menjadi dua bagian yaitu pengambilan keputusan (decision making) dan keputusan untuk membantu (decision ading)[10].

Langkah-langkah proses perhitungan menggunakan metode MEC, yaitu [4]

1) Menentukan faktor dan bobot faktor dimana total pembobotan harus sama dengan $1\left(\sum\right.$ pembobotan $=1$ ) atau disebut factor weight.

2) Mengisikan nilai tiap faktor yang di perlukan dalam proses pengambilan keputusan, nilai yang dimasukan merupakan nilai objektif yaitu factor evaluation yang nilainya $0-1$

3) Proses perhitungan weight evaluation merupakan perhitungan antara factor weight dan factor evaluation dengan penjumlahan, dari hasil weight evaluation dapat menentukan hasil evaluasi.

Dari langkah proses perhitungan menggunakan metode MEC diatas dapat direalisasikan sebagai berikut :

1) Perhitungan nilai bobot evaluasi faktor ditunjukan dalam persamaan (1).

$E F=\frac{\sum x}{\sum x \max }$

(1)

Keterangan

EF : Evaluasi Faktor

$\mathrm{X} \quad$ : Nilai Sub Kriteria

$\mathrm{X} \max \quad$ : Nilai $\mathrm{x} \max$

2) Perhitungan nilai bobot evaluasi ditunjukan dalam persamaan (2)

$W E=F W \times E$

(2)

Keterangan : 
WE

: Nilai bobot evaluasi

FW : Nilai bobot faktor

E : Nilai evaluasi faktor

3) Perhitungan nilai total evaluasi ditunjuk dalam persamaan (3)

$\sum_{i=1}^{n} W E_{i}=W E_{i}+W E_{2}+W E_{n}$

(3)

Keerangan

$\sum_{i=1}^{n} W E_{i} \quad$ : Total nilai bobot evaluasi

$W E_{i} \quad:$ Nilai bobot evaluasi ke $-\mathrm{i}$

2.5 Tahapan Penelitian

Adapun tahapan penelitian ini adalah :

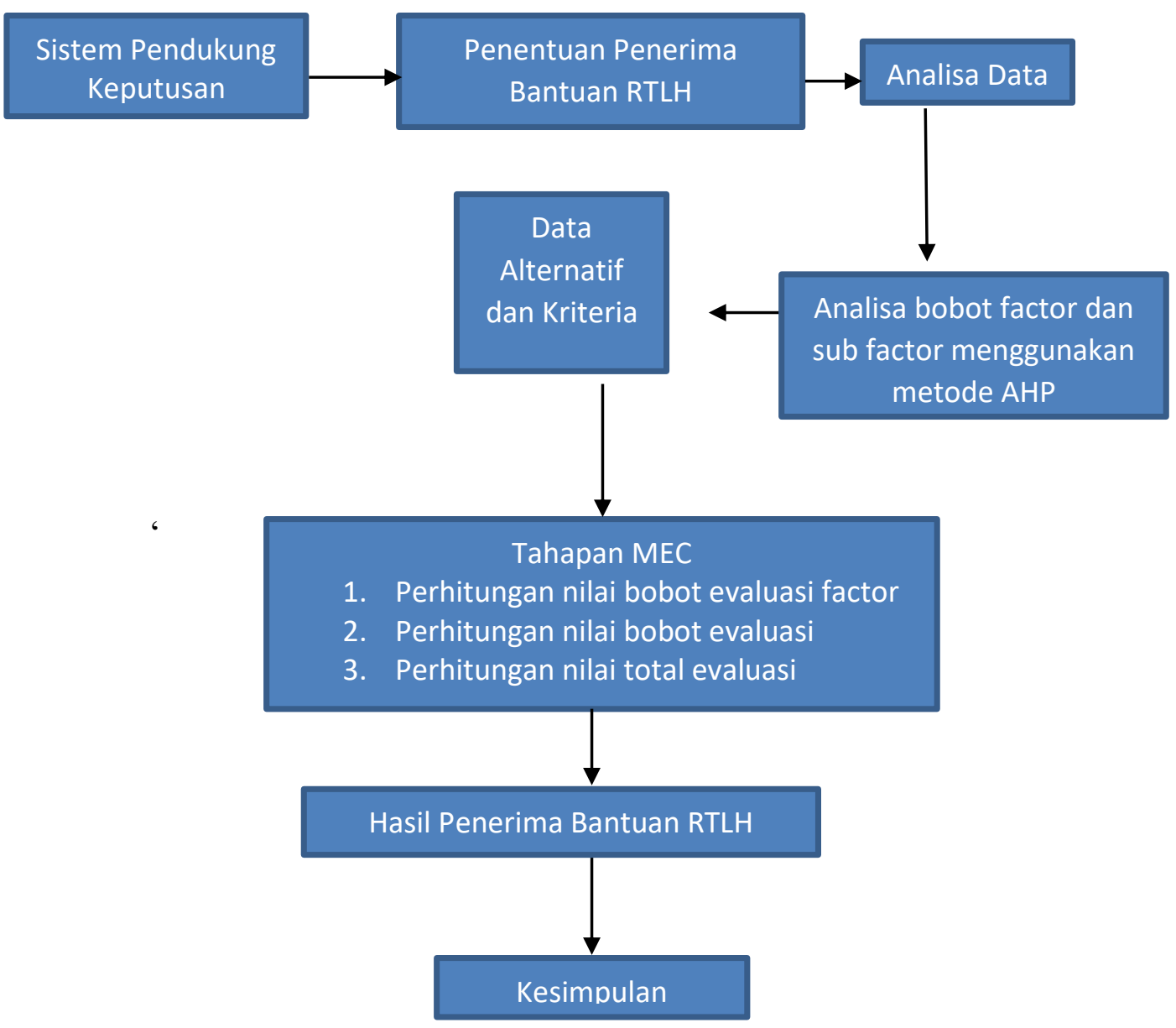

Gambar 2 Tahapan Penelitian

\section{HASIL DAN PEMBAHASAN}

Pada proses ini untuk mendapatkan bobot faktor dan sub faktor digunakan metode AHP. Faktor dan Sub Faktor yang menjadi pendukung dalam seleksi penerimaan bantuan rumah tidak layak huni dapat dilihat pada tabel 2 di bawah ini : 
Tabel 2 Faktor dan Sub Faktor

\begin{tabular}{|c|c|c|}
\hline No & Faktor & Sub Faktor \\
\hline \multirow{3}{*}{1} & \multirow{3}{*}{ Penghasilan } & $<$ Rp.500.000 \\
\hline & & Rp.550.000 - Rp.1.500.000 \\
\hline & & >Rp.1.500.000 \\
\hline \multirow{4}{*}{2} & \multirow{4}{*}{ Dinding } & Bambu \\
\hline & & Rotan \\
\hline & & Kayu \\
\hline & & Batu Bata \\
\hline \multirow{3}{*}{3} & \multirow{3}{*}{ Luas } & $<7 \mathrm{~m}^{2} /$ orang \\
\hline & & $7 \mathrm{~m}^{2} /$ orang $-10 \mathrm{~m}^{2} /$ orang \\
\hline & & $>10 \mathrm{~m}^{2} /$ orang \\
\hline \multirow{2}{*}{4} & \multirow{2}{*}{ Lantai } & Tanah \\
\hline & & Plesteran \\
\hline \multirow{3}{*}{5} & \multirow{3}{*}{ Atap } & Welit \\
\hline & & Genteng Bambu \\
\hline & & Genteng Kayu \\
\hline \multirow{2}{*}{6} & \multirow{2}{*}{ Jenis Rumah } & Panggung \\
\hline & & Gedong \\
\hline
\end{tabular}

Langkah selanjutnya menentukan nilai perbandingan dengan membuat matrik perbandingan berpasangan dari faktor dan Sub Faktor yang sudah didapatkan. Penilaian berdasarkan hasil wawancara pada Dinas Sosial. Matrik berpasangan ini dapat dilihat pada tabel di bawah ini :

1. Matrik Perbandingan Berpasangan Faktor

Tabel 3 Matriks Perbandingan Berpasangan Faktor

\begin{tabular}{|l|c|c|c|c|c|c|}
\hline \multicolumn{1}{|c|}{ Faktor } & Penghasilan & Dinding & Luas & Lantai & Atap & Jenis Rumah \\
\hline Penghasilan & 1 & 5 & 5 & 5 & 3 & 3 \\
\hline Dinding & 0,2 & 1 & 1 & 1 & 0,33 & 0,33 \\
\hline Luas & 0,2 & 1 & 1 & 1 & 0,33 & 0,33 \\
\hline Lantai & 0,2 & 1 & 1 & 1 & 0,33 & 0,33 \\
\hline Atap & 0,33 & 3 & 3 & 3 & 1 & 1 \\
\hline Jenis Rumah & 0,33 & 3 & 3 & 3 & 1 & 1 \\
\hline Jumlah & 2,2667 & 14 & 14 & 14 & 6 & 6 \\
\hline
\end{tabular}

2. Matrik Perbandingan Berpasangan Sub Faktor

Tabel 4 Matrik Perbandingan Berpasangan Sub Faktor Penghasilan

\begin{tabular}{|l|c|c|c|}
\hline \multicolumn{1}{|c|}{ Penghasilan } & $<$ Rp.500.000 & Rp.550.000 - Rp. 1.500 .000 & $>$ Rp. 1.500 .000 \\
\hline$<$ Rp.500.000 & 1 & 2 & 3 \\
\hline Rp.550.000 - Rp.1.500.000 & 0,5 & 1 & 2 \\
\hline$>$ Rp.1.500.000 & 0,33 & 0,5 & 1 \\
\hline Jumlah & 1,83 & 3,5 & 6 \\
\hline
\end{tabular}

Tabel 5 Matrik Perbandingan Berpasangan Sub Faktor Dinding

\begin{tabular}{|l|c|c|c|c|}
\hline \multicolumn{1}{|c|}{ Dinding } & Bambu & Rotan & Kayu & Batu Bata \\
\hline Bambu & 1 & 2 & 3 & 5 \\
\hline Rotan & 0,5 & 1 & 2 & 3 \\
\hline Kayu & 0,33 & 0,5 & 1 & 2 \\
\hline Batu Bata & 0,2 & 0,33 & 0,5 & 1 \\
\hline Jumlah & 2,03 & 3,83 & 6,5 & 11 \\
\hline
\end{tabular}


Tabel 6 Matrik Perbandingan Berpasangan Sub Faktor Luas

\begin{tabular}{|l|c|c|c|}
\hline \multicolumn{1}{|c|}{ Luas } & $<7 \mathrm{~m}^{2} /$ orang & $\begin{array}{l}7 \mathrm{~m}^{2} / \text { orang } \\
10 \mathrm{~m}^{2} / \text { orang }\end{array}$ & $>10 \mathrm{~m}^{2} /$ orang \\
\hline$<7 \mathrm{~m}^{2} /$ orang & 1 & 2 & 5 \\
\hline $7 \mathrm{~m}^{2}$ orang - & 0,5 & 1 & 2 \\
$10 \mathrm{~m}^{2} /$ orang & & & 1 \\
\hline$>10 \mathrm{~m}^{2} /$ orang & 0,2 & 0,5 & 8 \\
\hline Jumlah & 1,7 & 3,5 & 1 \\
\hline
\end{tabular}

Tabel 7 Matrik Perbandingan Berpasangan Sub Faktor Lantai

\begin{tabular}{|l|c|c|}
\hline \multicolumn{1}{|c|}{ Lantai } & Tanah & Plesteran \\
\hline Tanah & 1 & 3 \\
\hline Plesteran & 0,33 & 1 \\
\hline Jumlah & 1,33 & 4 \\
\hline
\end{tabular}

Tabel 8 Matrik Perbandingan Berpasangan Sub Faktor Atap

\begin{tabular}{|l|c|c|c|}
\hline \multicolumn{1}{|c|}{ Atap } & Welit & Genteng Bambu & Genteng Kayu \\
\hline Welit & 1 & 3 & 5 \\
\hline Genteng Bambu & 0,33 & 1 & 2 \\
\hline Genteng Kayu & 0,2 & 0,5 & 1 \\
\hline Jumlah & 1,53 & 4,5 & 8 \\
\hline
\end{tabular}

Tabel 9 Matrik Perbandingan Berpasangan Sub Faktor Jenis Rumah

\begin{tabular}{|l|l|l|}
\hline Jenis Rumah & Panggung & Gedong \\
\hline Panggung & 1 & 3 \\
\hline Gedong & 0,3 & 1 \\
\hline Jumlah & 1,3 & 4 \\
\hline
\end{tabular}

Setelah membuat matrik langkah selanjutnya menghitung prioritas dan nilai pembobotan untuk setiap masing-masing faktor dan sub-faktor. Menghitung bobot atau prioritas dengan melakukan manipulasi matriks atau diselesaikan dengan persamaan matematik. Kuadratkan matriks hasil perbandingan berpasangan untuk memperoleh keseluruhan prioritas dengan mempertimbangkan perbandingan berpasangan disintesis, jumlah nilai dari setiap baris dihitung, kemudian normalisasi matriks pun dilakukan. Hasil dari pembobotan dapat di lihat pada tabel di bawah ini :

1. Nilai Pembobotan Faktor

Tabel 10 Nilai Pembobotan Faktor

\begin{tabular}{|c|l|c|}
\hline No & Faktor & Bobot Faktor \\
\hline 1 & Penghasilan & 0,419 \\
\hline 2 & Dinding & 0,069 \\
\hline 3 & Luas & 0,069 \\
\hline 4 & Lantai & 0,069 \\
\hline 5 & Atap & 0,187 \\
\hline 6 & Jenis Rumah & 0,187 \\
\hline \multicolumn{2}{|c|}{ Total $\Sigma$} & 1 \\
\hline
\end{tabular}

2. Nilai Pembobotan Sub Faktor

Tabel 11 Nilai Pembobotan Sub Faktor Penghasilan

\begin{tabular}{|c|l|c|}
\hline No & \multicolumn{1}{|c|}{ Sub Faktor } & Bobot Sub Faktor \\
\hline 1 & $<$ Rp.500.000 & 0,539 \\
\hline 2 & Rp.550.000 - Rp.1.500.000 & 0,297 \\
\hline
\end{tabular}




\begin{tabular}{|c|c|c|}
\hline 3 & $>$ Rp. 1.500 .000 & 0,163 \\
\hline & Total $\sum$ & 1 \\
\hline
\end{tabular}

Tabel 12 Nilai Pembobotan Sub Faktor Dinding

\begin{tabular}{|l|l|c|}
\hline No & Sub Faktor & Bobot Sub Faktor \\
\hline 1 & Bambu & 0,483 \\
\hline 2 & Rotan & 0,272 \\
\hline 3 & Kayu & 0,157 \\
\hline 4 & Batu Bata & 0,088 \\
\hline & Total $\sum$ & 1 \\
\hline
\end{tabular}

Tabel 13 Nilai Pembobotan Sub Faktor Luas

\begin{tabular}{|l|l|c|}
\hline No & Sub Faktor & Bobot Sub Faktor \\
\hline 1 & $<7 \mathrm{~m}^{2} /$ orang & 0,595 \\
\hline 2 & $7 \mathrm{~m}^{2} /$ orang $-10 \mathrm{~m}^{2} /$ orang & 0,277 \\
\hline 3 & $>10 \mathrm{~m}^{2} /$ orang & 0,129 \\
\hline \multicolumn{2}{|c|}{ Total $\sum$} & 1 \\
\hline
\end{tabular}

Tabel 14 Nilai Pembobotan Sub Faktor Lantai

\begin{tabular}{|l|l|c|}
\hline No & Sub Faktor & Bobot Sub Faktor \\
\hline 1 & Tanah & 0,751 \\
\hline 2 & Plesteran & 0,249 \\
\hline
\end{tabular}

Tabel 15 Nilai Pembobotan Sub Faktor Atap

\begin{tabular}{|l|l|c|}
\hline No & Sub Faktor & Bobot Sub Faktor \\
\hline 1 & Welit & 0,648 \\
\hline 2 & Genteng Bambu & 0,229 \\
\hline 3 & Genteng Kayu & 0,122 \\
\hline & Total $\sum$ & 1 \\
\hline
\end{tabular}

Tabel 16 Nilai Pembobotan Sub Faktor Jenis Rumah

\begin{tabular}{|l|l|c|}
\hline No & Sub Faktor & Bobot Sub Faktor \\
\hline 1 & Panggung & 0,751 \\
\hline 2 & Gedong & 0,249 \\
\hline & Total $\Sigma$ & 1 \\
\hline
\end{tabular}

3. Nilai Bobot Faktor dan Sub Faktor

Nilai bobot faktor dan sub faktor merupakan persamaan (1) atau disebut factor weigth.

Tabel 17 Nilai Bobot Faktor dan Sub Faktor

\begin{tabular}{|c|c|c|c|c|}
\hline No & Faktor & Bobot Faktor & Sub Faktor & Bobot Sub Faktor \\
\hline \multirow{3}{*}{1} & \multirow{3}{*}{ Penghasilan } & \multirow{3}{*}{0,419} & $<$ Rp.500.000 & 0,539 \\
\hline & & & Rp.550.000 - Rp.1.500.000 & 0,297 \\
\hline & & & $>$ Rp.1.500.000 & 0,163 \\
\hline & & & Total $\sum$ & 1 \\
\hline \multirow{4}{*}{2} & \multirow{4}{*}{ Dinding } & \multirow{4}{*}{0,069} & Bambu & 0,483 \\
\hline & & & Rotan & 0,272 \\
\hline & & & Kayu & 0,157 \\
\hline & & & Batu Bata & 0,088 \\
\hline & & & Total $\sum$ & 1 \\
\hline
\end{tabular}




\begin{tabular}{|c|c|c|c|c|}
\hline \multirow{3}{*}{3} & \multirow{3}{*}{ Luas } & \multirow{3}{*}{0,069} & $<7 \mathrm{~m}^{2} /$ orang & 0,595 \\
\hline & & & $7 \mathrm{~m}^{2} /$ orang $-10 \mathrm{~m}^{2} /$ orang & 0,277 \\
\hline & & & $>10 \mathrm{~m}^{2} /$ orang & 0,129 \\
\hline & & & Total $\sum$ & 1 \\
\hline \multirow{2}{*}{4} & \multirow{2}{*}{ Lantai } & \multirow{2}{*}{0,069} & Tanah & 0,751 \\
\hline & & & Plesteran & 0,249 \\
\hline & & & Total $\sum$ & 1 \\
\hline \multirow{3}{*}{5} & \multirow{3}{*}{ Atap } & \multirow{3}{*}{0,187} & Welit & 0,648 \\
\hline & & & Genteng Bambu & 0,229 \\
\hline & & & Genteng Kayu & 0,122 \\
\hline & & & Total $\sum$ & 1 \\
\hline \multirow{2}{*}{6} & \multirow[t]{2}{*}{ Jenis Rumah } & \multirow{2}{*}{0,187} & Panggung & 0,751 \\
\hline & & & Gedong & 0,249 \\
\hline & & & Total $\sum$ & 1 \\
\hline & Total $\sum$ & 1 & & \\
\hline
\end{tabular}

4. Pengisian nilai sub faktor dari peserta penerima bantuan

Pada tahap ini peneliti mencoba melakukan sampel perhitungan teradap beberapa peserta penerima bantuan dengan memasukan nila dari sub faktor.

Tabel 18 Nilai Sub Faktor dan Alternatif

\begin{tabular}{|l|c|c|c|c|c|c|}
\hline \multirow{2}{*}{$\begin{array}{c}\text { Alternatif } \\
\text { (Peserta) }\end{array}$} & \multicolumn{7}{|c|}{ Faktor } \\
\cline { 2 - 7 } & Penghasilan & Dinding & Luas & Lantai & Atap & $\begin{array}{c}\text { Jenis } \\
\text { Rumah }\end{array}$ \\
\hline Supardi & 0,297 & 0,483 & 0,129 & 0,751 & 0,229 & 0,751 \\
\hline Sofian & 0,163 & 0,088 & 0,595 & 0,249 & 0,648 & 0,751 \\
\hline Muhammad Aziz & 0,297 & 0,272 & 0,277 & 0,751 & 0,122 & 0,249 \\
\hline
\end{tabular}

5. Langkah selanjutnya adalah melakukan proses perhitungan weight evaluation. Proses ini menggunakan persamaan (2). Berikut adalah perhitungan weight evaluation.

a) Weight Evalaution Penghasilan

$$
\begin{aligned}
\mathrm{W}_{\text {Supardi }} & =0,297 * 0,419 \\
& =0,125 \\
\mathrm{~W}_{\text {Sofian }} & =0,163 * 0,419 \\
& =0,068 \\
\mathrm{~W}_{\text {Muhammad Aziz }} & =0,297 * 0,419 \\
& =0,125
\end{aligned}
$$

b) Weight Evalaution Dinding

$$
\begin{aligned}
\mathrm{W}_{\text {Supardi }} & =0,483 * 0,069 \\
& =0,033 \\
\mathrm{~W}_{\text {Sofian }} & =0,088 * 0,069 \\
& =0,006 \\
\mathrm{~W}_{\text {Muhammad Aziz }} & =0,272 * 0,069 \\
& =0,019
\end{aligned}
$$

c) Weight Evalaution Luas

$$
\begin{aligned}
\mathrm{W}_{\text {Supardi }} & =0,129 * 0,069 \\
& =0,009 \\
\mathrm{~W}_{\text {Sofian }} & =0,595 * 0,069 \\
& =0,041 \\
\mathrm{~W}_{\text {Muhammad Aziz }} & =0,277 * 0,069 \\
& =0,019
\end{aligned}
$$


d) Weight Evaluation Lantai

$$
\begin{aligned}
\mathrm{W}_{\text {Supardi }} & =0,751 * 0,069 \\
& =0,052 \\
\mathrm{~W}_{\text {Sofian }} & =0,249 * 0,069 \\
& =0,017 \\
\mathrm{~W}_{\text {Muhammad Aziz }} & =0,751 * 0,069 \\
& =0,052
\end{aligned}
$$

e) Weight Evalaution Atap

$$
\begin{array}{ll}
\mathrm{W}_{\text {Supardi }} & =0,229 * 0,187 \\
& =0,042 \\
\mathrm{~W}_{\text {Sofian }} & =0,648 * 0,187 \\
& =0,121 \\
\mathrm{~W}_{\text {Muhammad Aziz }} & =0,122 * 0,187 \\
& =0,023
\end{array}
$$

f) Weight Evaluation Jenis Rumah

$$
\begin{array}{ll}
\mathrm{W}_{\text {Supardi }} & =0,751 * 0,187 \\
& =0,140 \\
\mathrm{~W}_{\text {Sofian }} & =0,751 * 0,187 \\
& =0,140 \\
\mathrm{~W}_{\text {Muhammad Aziz }} & =0,249 * 0,187 \\
& =0,047
\end{array}
$$

Hasil keseluruhan weight evaluation :

Tabel 19 Nilai Weight Evalaution Setiap Alternatif

\begin{tabular}{|l|c|c|c|c|c|c|}
\hline \multirow{2}{*}{$\begin{array}{c}\text { Alternatif } \\
\text { (Peserta) }\end{array}$} & \multicolumn{7}{c|}{ Faktor } \\
\cline { 2 - 7 } & Penghasilan & Dinding & Luas & Lantai & Atap & $\begin{array}{c}\text { Jenis } \\
\text { Rumah }\end{array}$ \\
\hline Supardi & 0,125 & 0,033 & 0,009 & 0,052 & 0,042 & 0,140 \\
\hline Sofian & 0,068 & 0,006 & 0,041 & 0,017 & 0,121 & 0,140 \\
\hline Muhammad Aziz & 0,125 & 0,019 & 0,019 & 0,052 & 0,023 & 0,047 \\
\hline
\end{tabular}

6. Setelah nilai weight evalaution setiap alternatif didapatkan maka langkah selanjutnya melakukan perhitungan nilai total evaluasi ditunjuk dalam persamaan (3)

$$
\begin{array}{ll}
\sum W_{\text {supardi }} & =0,125+0,033+0,009+0,052+0,042+0,140 \\
\sum W_{\text {Sofian }} & =0,401 \\
\sum W_{\text {Muahhamd Aziz }} & =0,068+0,006+0,041+0,017+0,121+0,140 \\
& =0,393 \\
& =0,285
\end{array}
$$

Total evaluasi setiap alternatif :

Tabel 20 Total Evaluasi

\begin{tabular}{|l|c|c|c|c|c|c|c|}
\hline \multirow{2}{*}{$\begin{array}{c}\text { Alternatif } \\
\text { (Peserta) }\end{array}$} & \multicolumn{7}{|c|}{ Faktor } \\
\cline { 2 - 8 } & Penghasilan & Dinding & Luas & Lantai & Atap & $\begin{array}{c}\text { Jenis } \\
\text { Rumah }\end{array}$ & $\sum \mathrm{W}$ \\
\hline Supardi & 0,125 & 0,033 & 0,009 & 0,052 & 0,042 & 0,140 & 0,401 \\
\hline Sofian & 0,068 & 0,006 & 0,041 & 0,017 & 0,121 & 0,140 & 0,393 \\
\hline $\begin{array}{l}\text { Muhammad } \\
\text { Aziz }\end{array}$ & 0,125 & 0,019 & 0,019 & 0,052 & 0,023 & 0,047 & 0,285 \\
\hline
\end{tabular}

Berdasarkan tabel 20 diatas, dapat dilihat bahwa Supardi peserta bantuan rumah tidak layak huni memiliki nilai tertinggi, maka dari itu dilihat dari nilai peranngkingan Supardi merupakan peserta yang mendapat bantuan untuk rumah tidak layak huni. 


\section{KESIMPULAN}

Berdasarkan uraian dan perhitungan diatas, kesimpulan yang didapat adalah :

1. Pada proses pembobotan faktor dan sub faktor menggunakan metode AHP ini bisa menghasilkan bobot factor dan sub factor sehingga bobot tersebut bisa dilanjutkan dengan tahapan MEC.

2. Pengisian tingkat kepetingan untuk penilaian bobot faktor dan sub faktor sangat berpengaruh dalam proses penilaian pembobotan.

3. Metode MEC dan AHP mampu berkolaborasi untuk mendapatkan total penilaian berupa perangkingan.

4. Dalam perhitungan sampel diatas menggunakan metode MEC dan AHP mendapatkan hasil peserta bernama Supardi sebagai penerima bantuan rumah tidak layak huni dengan nilai 0,401 .

\section{SARAN}

Penelitian ini masih menggunakan sampel data dari beberapa peserta yang ada di Kelurahan Dempo Kecamatan Lubuklinggau Timur II Kota Lubuklinggau. Agar lebih ideal maka diharapkan data yang didapatkan berupa data semua peserta penerimaan bantuan rumah tidak layak huni yang berada di Kota Lubuklinggau, sehingga program pemberian bantuan ini dapat tersalurkan secara sistematis dengan menggunakan metode ini.

\section{DAFTAR PUSTAKA}

[1] V. Listyaningsih, H. Setiawan, E. Sudrajat, and R. P. Kristianto, "DSS Pemilihan Penerima Bantuan Perbaikan Rumah dengan Metode Weight Product (WP)," Semin. Nas. Teknol. Inf. dan Multimed., no. October 2017, pp. 6-7, 2016.

[2] T. Sugihartono, D. Ardiansyah, and M. Zakky, "Implementasi Sistem Pendukung Keputusan Penerima Bantuan Rumah Tidak Layak Huni Berbasis Web,"Jurnal Sisfokom., vol. 07, no. May, pp. 52-56, 2018.

[3] I. Jamaludin, N. Sudarsono, and A. I. Mustika, "Sistem Penunjang Keputusan Kelayakan Penerima Bantuan Dana Rutilahu Dengan Metode Ahp," Semin. Nas. Inform., vol. 1, no. 1, pp. 276-283, 2017.

[4] Y. Primadasa and V. Amalia, "Penerapan Metode Multi Factor Evaluation Process untuk Pemilihan Tanaman Pangan di Kabupaten Musi Rawas," J. Sisfo, vol. 07, no. 01, pp. 4758, 2017.

[5] M. S. Hossain, S. R. Chowdhury, N. G. Das, and M. M. Rahaman, "Multi-criteria evaluation approach to GIS-based land-suitability classification for tilapia farming in Bangladesh," Aquac. Int., vol. 15, no. 6, pp. 425-443, 2007.

[6] I. Umar, B. Pramudya, P. S. Geografi, F. Ilmu, S. Unp, and K. Airtawar, "Evaluasi Kesusian Lahan Untuk Kawasan Permukiman Dengan Metode Multi Criteria Evaluation Di Kota Padang," Jurnal Pengelolaan Sumberdaya Alam dan Lingkungan.,vol. 7, no. 2, pp. 148-154, 2017.

[7] R. Yanto, "Sistem Pendukung Keputusan Prioritas Investasi dalam upaya Peningkatan Kualitas Perguruan Tinggi," J. RESTI (Rekayasa Sist. dan Teknol. Informasi), vol. 1, no. 3, pp. 211-216, 2017.

[8] Y. K. dan A. Rizeki, "Sistem Pendukung Keputusan Distribusi Rehabilitas Sosial Rumah Tidak Layak Huni pada Kab Sampang Menerapkan Metode Vikor," Seinar Nas. Teh. Inform. Univ. Malikussaleh, vol. 8, No 1 (2, no. 1, pp. 1-13, 2107.

[9] Asria,dkk, "Model Analytical Hierarchy Proscess Untuk Sistem Pendukung Keputusan Penilaian Karyawan Pada Instansi Kesatuan Bangsa Politik dan Perlindungan Masyrakat Propinsi Jawa Tengah", Techno.Com., vol. 12, no. 4, pp. 223-230, 2013.

[10] M. N. Ahmad Jazuli, "Fakultas Teknik - Universitas Muria Kudus 269," Sist. Pendukung Keputusan Untuk Penentuan Rumah TIdak Layak Huni di Cangkring Rembang Kec. Karanganyar Demak, Prosiding SNATIF., pp. 269-276, 2016. 